\title{
Is pancreas development abnormal in the non-obese diabetic mouse, a spontaneous model of type I diabetes?
}

\section{F. Homo-Delarche}

\section{Correspondence}

F. Homo-Delarche

CNRS U M R 8603, Hôpital Necker

161 , rue de Sèvres

75015 Paris

France

Fax: +33-1-4449-0676

E-mail: fhomodel@ wanadoo.fr

Presented at

SIMEC 2000 - International

Symposium on Extracellular

Matrix, Angra dos Reis, RJ,

Brazil, September 24-27, 2000.

Research supported by grants from CNRS, Université Paris V, Fondation de France, ALFEDIAM (associated with Lilly Laboratories), IN SERM CNPq and IN SERM-NWO, BIO MED (Betimmune) and 5th PCRD (Monodiab).

Received October 19, 2000 Accepted February 6, 2001

\author{
CNRS U M R 8603, U niversité Paris V, Hôpital N ecker, Paris, France
}

\section{Abstract}

Despite extensive genetic and immunological research, the complex etiology and pathogenesis of type I diabetes remains unresolved. During the last few years, our attention has been focused on factors such as abnormalities of islet function and/or microenvironment, that could interact with immune partners in the spontaneous model of the disease, the non-obese diabetic (NOD) mouse. Intriguingly, the first anomalies that we noted in NOD mice, compared to control strains, are already present at birth and consist of 1) higher numbers of paradoxically hyperactive $\beta$ cells, assessed by in situ preproinsulin II expression; 2) high percentages of immature islets, representing islet neogenesis related to neonatal $ß$-cell hyperactivity and suggestive of in utero ß-cell stimulation; 3 ) elevated levels of some types of antigenpresenting cells and $\mathrm{FasL}^{+}$cells, and 4) abnormalities of extracellular matrix (ECM) protein expression. However, the colocalization in all control mouse strains studied of fibroblast-like cells (anti-TR-7 labeling), some ECM proteins (particularly, fibronectin and collagen I), antigen-presenting cells and a few FasL ${ }^{+}$cells at the periphery of islets undergoing neogenesis suggests that remodeling phenomena that normally take place during postnatal pancreas development could be disturbed in NOD mice. These data show that from birth onwards there is an intricate relationship between endocrine and immune events in the NOD mouse. They also suggest that tissue-specific autoimmune reactions could arise from developmental phenomena taking place during fetal life in which ECM-immune cell interaction(s) may play a key role.

\section{Introduction}

Type I diabetes is one of the most frequent chronic diseases of children caused by the autoimmune destruction of pancreatic insulin-producing $\beta$ cells (insulitis) (1). Because human pancreatic tissue is unavailable, our present understanding of the pathogenesis of type I diabetes has been made possible over the past two decades by the existence of two spontaneous animal models
Key words

- NOD mice

- Postnatal pancreas

development

- Antigen-presenting cell

- Extracellular matrix of the disease: the BioBreeding rat and the non-obese diabetic (NOD) mouse $(1,2)$. The immune reaction against $\beta$ cells occurs on a multigenic susceptibility background, while environmental and hormonal factors modulate disease development (1-3). However, despite major progress in the elucidation of genetic and immune mechanisms, several issues of theoretical significance remain unresolved, among which perhaps the most important one, i.e., the initial trigger for break- 
ing self tolerance, is unknown.

NOD mice develop autoimmunity towards islets of Langerhans around weaning (3 weeks of age). The results of many studies have implicated defective regulation of immune function (2). This explanation, however, does not take into account that the autoimmune process is strongly organ specific. While abnormalities of immune regulation may explain the predisposition to autoimmunity in general, additional factors probably determine the specific target of the autoimmune attack and, particularly, the target organ itself. We hypothesized that defects in islet differentiation and/or function could drive the immune system towards islet autoimmunity (4) and therefore investigated various immune and endocrine parameters during the early prediabetic stage in NOD mice.

\section{Antigen-presenting cell infiltration and islet abnormalities in prediabetic NOD mice}

We showed that in wild-type NOD mice the first sign of infiltration is an accumula- tion of CD1 $1 \mathrm{c}^{+}$dendritic cells (DC) around the islets from about 3-4 weeks onwards, i.e., notably around weaning. At the same time, ER-MP23 ${ }^{+}$and MOMA- ${ }^{+}$macrophages $(\mathrm{M} \phi)$, normally present in the exocrine pancreas, migrate to the periphery of the islets (5). Surprisingly, in lymphocytedeficient NODscid mice, the same antigenpresenting cell (APC) infiltration takes place, albeit with fewer cells (6). In NOD mice, subsequent $\mathrm{T}$-cell migration to the pancreas and home around the islets (peri-insulitis) is followed by APC and T-cell infiltration into the islets (insulitis) (7). Destructive insulitis coincides with $\mathrm{BM}^{+} \mathrm{M} \phi$ infiltration and finally leads to $\beta$-cell destruction and the resulting symptoms of type I diabetes (5-7).

Until now, we and others have described several abnormalities of the islets of Langerhans and surrounding tissue in prediabetic NOD mice compared to one or several control strains. These abnormalities are summarized in Figure 1 and consist of: at birth increased B-cell apoptosis (8), B-cell hyperactivity (in situ hybridization) associated with higher numbers of immature islets, reflecting islet neogenesis (9), and mild infiltration
Figure 1 - Kinetics of abnormalities observed at the pancreas level in prediabetic female NOD mice. APC: Antigen-presenting cells; ECM: extracellular matrix GABA: gamma-aminobutyric acid; IHC: immunohistochemistry.

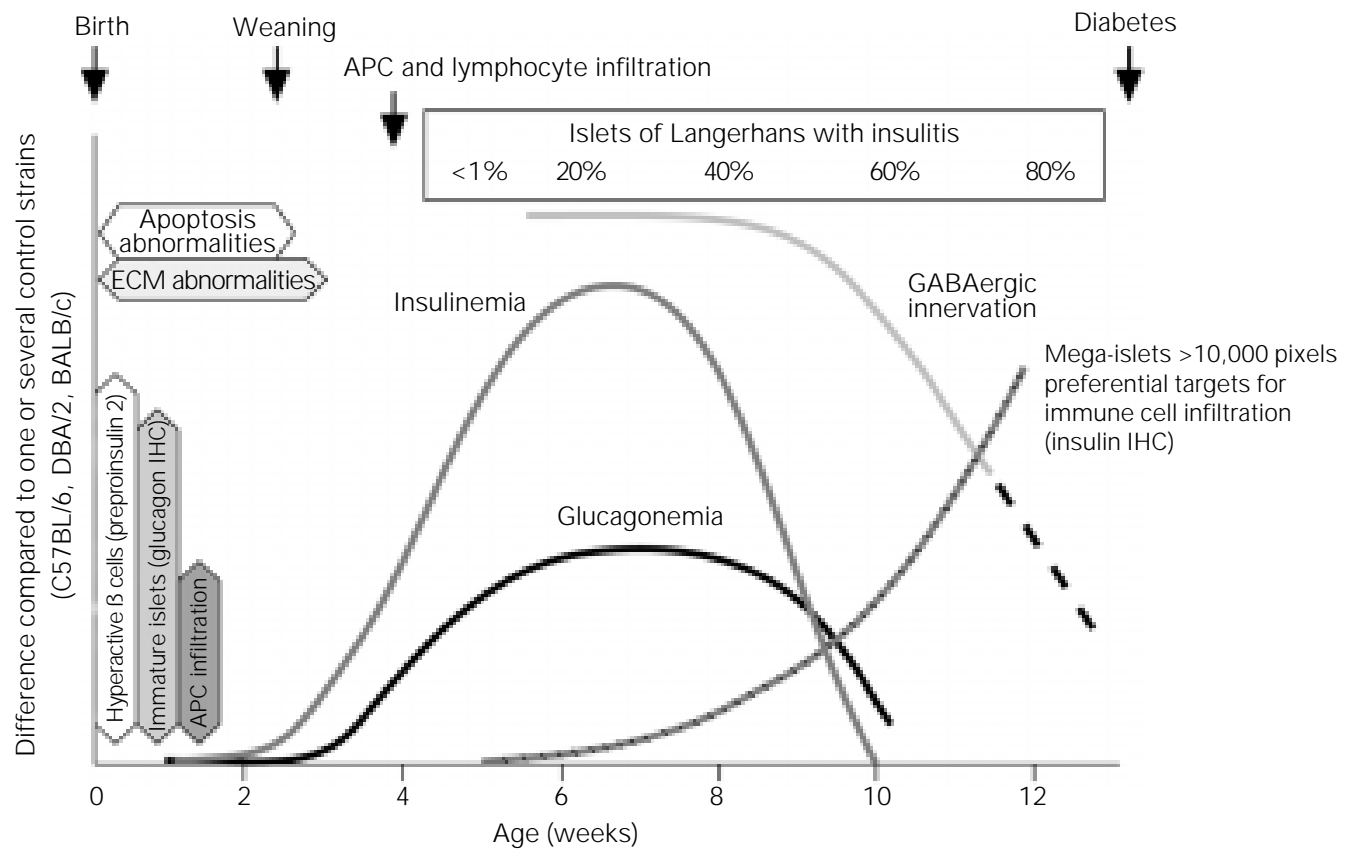


with DC and $M \phi(10)$; at 4-8 weeks of age high percentages of adult $\beta$-stem cells $(\mathrm{SOM}+\mathrm{PDX} 1+)(11)$, hyperinsulinemia (12), hyperglucagonemia (9), and progressive disappearance of GABAergic innervation (13); $>10$ weeks of age - mega-islet formation accompanied by extensive infiltration with $\mathrm{DC} / \mathrm{M} \phi$ and lymphocytes predominantly around these mega-islets (6). Finally, after 12 weeks of age, these prediabetic abnormalities are followed by the appearance of the first clinical signs of $\beta$-cell destruction, i.e., onset of clinical diabetes $(1,2)$.

It is worth noting that some of these pancreatic abnormalities - including mild $\mathrm{DC} / \mathrm{M} \phi$ infiltration - are present at birth and also in NOD mice bearing the scid mutation which lack functional lymphocytes $(1,6)$. Therefore, these anomalies 1) develop during fetal life, 2) are inherent to the NOD background, and 3) are not induced by lymphocytes. Moreover, the early mild perinatal, and later and stronger postweaning DC/ $\mathrm{M} \phi$ influxes have always been associated with abnormal islet differentiation and function. Finally, the localization of the early immune cell infiltration (APC and lymphocytes) was intriguing: around ducts and especially islets, where the targets of the autoimmune reaction, i.e., the $\beta$ cells, form the core of the islet and are surrounded by non$B$ cells. More particularly, we frequently found APC surrounding small islets connected to ducts (Figure 2), which correspond to islets undergoing neogenesis $(14,15)$. However, some types of these APC were also similarly localized in early postnatal pancreata from normal mouse strains (10). Therefore, these observations led us to consider the possibility of an abnormal pancreas development in mice with the NOD genetic background.

\section{A role for APC in pancreas development?}

The pancreas arises from an endodermal budding of the embryonic foregut into the surrounding mesenchyme (15). During branching, differentiation, morphogenesis and growth of the pancreas, mesenchymalepithelial cell interactions are important (16). Both endocrine and exocrine tissues are thought to arise from ductal epithelial stem cells through differential activation $(17,18)$. The pancreas reaches its adult size after weaning, due to the marked postnatal growth of pancreatic tissue, especially the exocrine compartment (14). Accordingly, in the pancreas of normal rodents, particularly until 4/ 5 weeks of age in mice, tissue remodeling phenomena exist, consisting of waves of neogenesis, cell replication and apoptosis $(19,20)$. A variety of cytokines and growth factors (such as IL-6, TNF- $\alpha$, IFN- $\gamma$, TGF- $\beta$, HGF, EGF, NGF, VEGF, IGFI and II) (21), cell-adhesion molecules (cadherins, neural cell adhesion molecule) (22) and extracellular matrix proteins (ECM) and metalloproteinases have been reported to be involved in

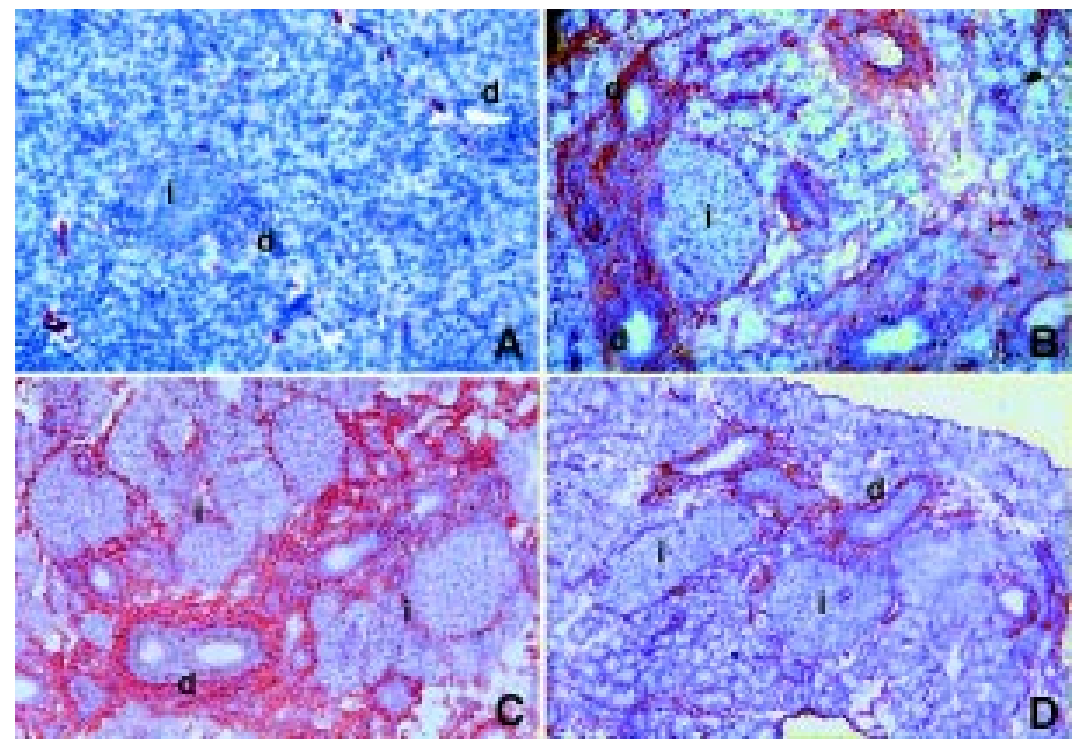

Figure 2 - A, Scavenger BM 8+ macrophages are present in the pancreas of control strains, at 2 weeks of age, and are scattered throughout the exocrine tissue and/or are in close contact to ducts (d) and islets (i) (320X). These cells are also observed in similar localizations in NOD mice; B, C, and D correspond to fibronectin (320X), collagen I (320X) and TR-7 (fibroblast-like cells) (200X), respectively, in the pancreata of one-week-old NOD mice. These molecules are labeled in perivascular, periductular and peri-islet localizations, as for $\mathrm{BM}^{+}$macrophages. Control strains show usually thinner labeling in the same localizations (data not shown). 
pancreas development $(17,23)$.

Although DC/M $\phi$ are potentially able to produce and/or degrade some of these factors, nothing is known about the role that these cells may have in mesenchymal-epithelial interactions, branching and islet and/ or acinar morphogenesis during pancreas development. This role could involve, for example, synthesis and degradation of ECM proteins, which are known to be controlled by metalloproteinases, synthesis of cytokines and growth factors, and apoptosis induction (24). Notably, APC and lymphocyte infiltrations have been seen during normal fetal pancreatic development in humans (25) and high numbers of APC were also observed in rat foregut during normal development (26). When we investigated the presence of different types of APC during early postnatal development in NOD strains and various control strains, we found in the latter at birth high numbers of macrophages, particularly scavenger $\mathrm{BM}^{+}$cells, scattered or in periductular and peri-islet areas, as previously described (10). However, their numbers subsided gradually and $\mathrm{BM}^{+}$cells disappeared completely during the postweaning period, in contrast to what happened in NOD mice. These data led us to hypothesize that macrophages are indeed involved in normal postnatal growth and differentiation. Our hypothesis has recently been strengthened by the observation that $\mathrm{M} \phi$, in association with eosinophils, are involved in normal postnatal mouse mammary gland development, by regulating branching morphogenesis (27).

\section{Is ECM protein involvement abnormal during postnatal NOD pancreas development?}

As regards the normal rodent pancreas, a few reports have shown in vitro that ECM proteins affect fetal or neonatal endocrine tissue development: laminin induces $\beta$-cell differentiation in mouse fetuses (28), fibronectin stimulates islet proliferation and insu- lin secretion in newborn rats (29), and collagen affects the islet distribution of $\beta$ versus non- $\beta$ cells (30). Moreover, the levels of some ECM-degrading metalloproteinases are able to affect in vitro rat islet morphogenesis (17). Recently, laminin and its receptor, the $\alpha 6$-containing integrin, have also been shown to play roles in vitro in ductal morphogenesis and the induction of exocrine tissue, respectively (31). In vivo, the expression of various ECM proteins has been evaluated during pancreas development in normal rats (23) and in TGF- $\beta 1$-transgenic mice (32). In the latter study, increased fibroblastic proliferation and accumulations of laminin and fibronectin were observed concomitant with decreased acinar proliferation together with macrophage and neutrophil infiltration. In this regard, the haptotactic properties of ECM proteins (mainly produced by fibroblasts) acting on leukocytes are well known (33).

To the best of our knowledge, ECM protein expression has not been assessed systematically during normal postnatal mouse development. Moreover, taking into account the various abnormalities present at birth in the NOD mouse, particularly the APC infiltration, we raised the hypothesis of an ECMrelated dysfunction during pancreas development in the NOD mouse. We therefore evaluated the expression of laminin and fibronectin and their corresponding integrin receptors (VLA6 for laminin, VLA4 and VLA5 for fibronectin) in the postnatal developing NOD pancreas, compared with various control mouse strains (Homo-Delarche F, Pleau JM, Durant S, Alves V, Coulaud J and Savino W, unpublished results). Preliminary data were also obtained for collagen I.

First, all molecules studied are present in mouse pancreata from birth onwards, as assessed by immunohistochemistry, and their mRNA expression was confirmed by the reverse transcriptase-polymerase chain reaction (RT-PCR). Second, various structures (for example, belonging to exocrine, endo- 
crine and connective tissues, and vessels and nerves) may be labeled by a given antibody. Third, the main conclusion is that, in all strains at birth, immaturity is found at the level of various pancreatic structures: endocrine, exocrine, vascular and neural, and this was most clearly demonstrated by VLA6 labeling. Moreover, at birth, this labeling highlighted wide connective septa in NOD and NODscid strains but they were labeled apparently in a nonspecific way by goat antimouse IgG and rabbit anti-rat IgG only in NOD mice and not NODscid mice (HomoDelarche F, unpublished data). Such labeling in NOD mice might be reminiscent of matrix alterations (matricryptic sites), occurring during tissue injury and providing important new signals to regulate the repair process (34). Fourth, some ECM proteins are well represented not only in perivascular and periductular areas but also at the ductularvascular pole of the islet of Langerhans, as illustrated in Figure 2B and C, for fibronectin and collagen I. It should be emphasized that these localizations, and particularly the ductular-vascular pole of islets in neoformation, are also those where $\mathrm{DC} / \mathrm{M} \phi$ are found, both in control and NOD strains during the early postnatal period. Fifth, in NOD mice around weaning, laminin- and fibronectinlabeled vessels and ducts appear larger, as do vessels immunoreacted for VLA5.

Since fibroblasts may produce these ECM molecules, we used the anti-TR-7 monoclonal antibody (TR-7mAb) which has been reported to recognize mouse fibroblasts (35). TR-7mAb labeling was observed at the same sites as ECM proteins (perivascular, periductular and peri-islet areas and vascularductular poles of islets; Figure 2D). Moreover, in one-month-old NOD mice, TR-7mAb labeling appeared denser in these areas and, curiously, in periacinar areas. In the latter localization, these cells might correspond to the periacinar fibroblast-like cells, which stimulate acinar cell proliferation and regeneration, and are involved in periacinar fibro- sis (36). Finally, the presence of TR $-7^{+}$fibroblast-like cells and ECM fibers coincides with that of primary infiltrating immune cells. However, it is worth noting that only a few macrophages (but not yet lymphocytes) are observed when many TR $-7^{+}$cells are already present.

In summary, this study on ECM proteins and their receptors clearly shows, for the first time, the immaturity of the mouse pancreas at birth, even in control strains. Moreover, postnatal NOD pancreas development exhibits several differences. Normally, immaturity also exists at birth at the salivary gland level, another foregut-derived organ (37) and target for the autoimmune reaction in NOD mice. Recently, NOD salivary glands were shown to undergo abnormal organogenesis, consisting of delayed morphological differentiation with wide connective septa, less acinar proliferation at birth, elevated activity of matrix metalloproteinase 9 along with collagen IV and increased expression of FasL, Fas and Bcl-2 (38). Taken together, these NOD mouse abnormalities might be a consequence of disturbed fetal foregut development. They also suggest that a more common pathophysiological mechanism than previously thought may underlie the progression of the autoimmune reaction at different organ levels in NOD mice but its clinical expression depends only on the target tissue itself. In this regard, it has already been suggested that organs derived from the same embryonal germ layer express common germ layer-specific antigens that could serve as target antigens for the autoimmune response (39).

Other pertinent conclusions of this study are: 1) islet neogenesis involves several ECM molecules and their receptors, in particular at the ductular-insular pole and its periphery, where we previously demonstrated the presence of various types of APC; 2) TR-7 $7^{+}$ fibroblast-like cells, as potential producers of ECM proteins, are also an abundant component in various areas and particularly at 
the islet periphery and ductular-insular pole.

These data highlight the extent of remodeling phenomena taking place in the early postnatal pancreas, in which fibroblasts and APC may play important roles even during normal development. Moreover, in NOD mice around weaning, vessels, ducts and islets in neoformation are clearly different in terms of size, as shown by the expression of ECM molecules and their receptors and TR$7^{+}$cells. The question therefore arises whether these remodeling phenomena are well controlled in the NOD mouse and, if not, at what level they are defective and to what extent they could be responsible for the autoimmune reaction.

\section{Are apoptosis and anti-apoptosis molecules abnormally expressed during postnatal NO D pancreas development?}

Since apoptotic phenomena are a normal component of development $(19,40)$, we searched for the expression of apoptosisand anti-apoptosis-related molecules (FasL, Fas and Bcl-2, as already done in salivary

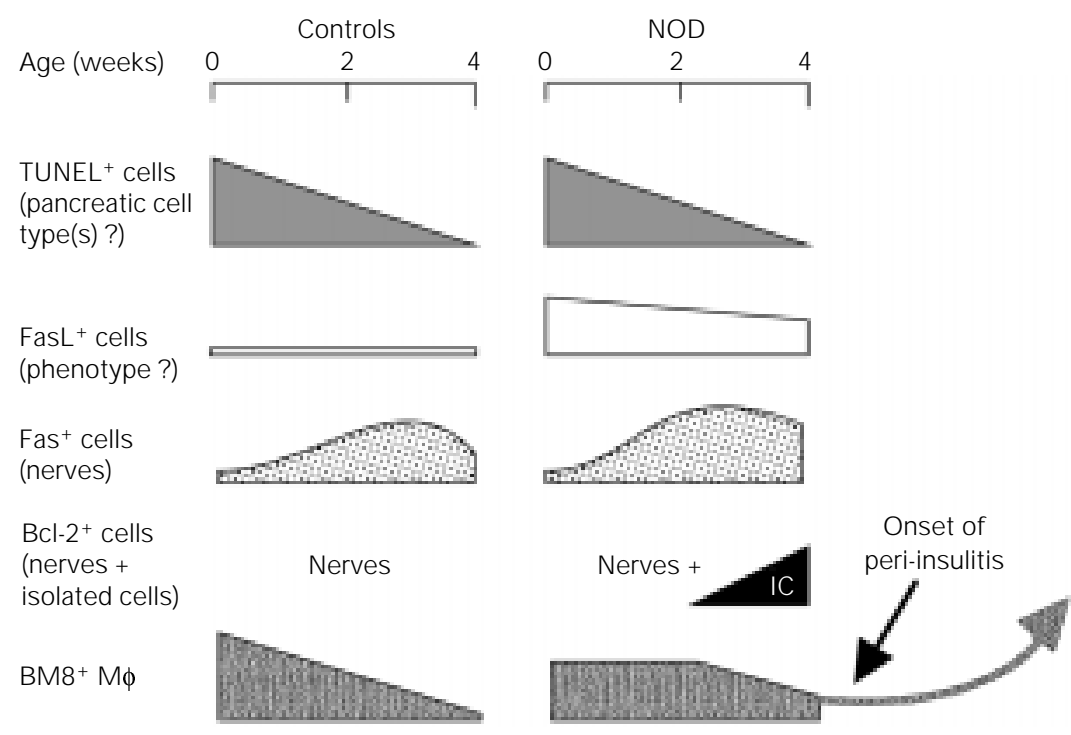

Figure 3 - Evolution of apoptosis (anti-apoptosis)-related phenomena and pancreatic BM8+ macrophage infiltration during the postnatal period in non-obese diabetic (NOD) mice. IC: Isolated cells; TUNEL: TdT-mediated dUTP-X nick end labeling. glands) in the pancreata of various control strains and NOD and NODscid mice, using immunohistochemistry and RT-PCR (Durant S, von Bockland S, Pleau JM, Coulaud J, Alves V, Versnel M and Homo-Delarche F, unpublished results).

The most impressive data concern the presence of high numbers of $\mathrm{FasL}^{+}$cells in mice with the NOD genetic background at birth. The numbers of FasL ${ }^{+}$cells in NOD strains decrease slightly with time during the first month of life, while in control strains, they are scarcely present regardless of the age studied. These cells are either scattered or, once again, are found in perivascular, periductular and peri-insular localizations and at the ductular-insular pole of the islet, as are APC and TR $-7^{+}$fibroblast-like cells. The phenotype of these $\mathrm{FasL}^{+}$cells has not yet been determined. It is worth noting that, while APC and fibroblast-like cells were always present in control strain pancreata during the postnatal period, the presence of high numbers of $\mathrm{FasL}^{+}$cells in the same localizations was specific to the NOD genetic background.

Because of the different infiltration patterns of $\mathrm{FasL}^{+}$cells, we wondered whether apoptosis differed among the various strains. We therefore assessed the numbers of apoptotic cells using the TdT-mediated dUTP-X nick end labeling (TUNEL) method. We chose to count all pancreatic apoptotic cells/ $\mathrm{mm}^{2}$, regardless of their type, taking into account the extra-insular distribution of $\mathrm{FasL}^{+}$ cells. We also searched for qualitative differences in Fas/Bcl-2 expression by target cells.

Figure 3 summarizes the kinetics of such determinant. First, the total numbers of pancreatic apoptotic cells do not appear to differ among strains, including NOD, but they appear to decrease gradually over the first month of life. However, by assessing only islet-cell apoptosis, other investigators found increased B-cell apoptosis in NOD mice from birth onwards (8). Second, as mentioned above, 
there are many $\mathrm{FasL}^{+}$cells in mice with the NOD genetic background from birth onwards and they do not disappear with time. Third, still only in NOD strains, a wave of isolated Bcl- $2^{+}$cells is observed at around 2 weeks of age and concomitantly, fibroblast-like cell infiltration appears to be denser. Fourth, when apoptotic cells are present during postnatal pancreas development, $\mathrm{BM}^{+}$scavenger $\mathrm{M} \phi$ are also observed, but their evolution pattern is quite different in NOD mice compared to controls, perhaps due to the presence of $\mathrm{FasL}^{+}$and Bcl- $2^{+}$cells. Finally and curiously, $\mathrm{Fas}^{+}$and $\mathrm{Bcl}-2^{+}$innervation is present during postnatal pancreas development in all strains.

Taken together, these data for NOD mice suggest a perturbation of apoptotic phenomena that takes place during postnatal pancreas development in which many actors may participate before any obvious lymphocyte infiltration. Moreover, these disturbances of pancreas development appear to be strongly dependent on the NOD genetic background because they are also observed, to some extent, in lymphocyte-deficient NODscid mice.

\section{Conclusion: Do studies on postnatal NOD pancreas development offer a new scenario for the pathogenesis of type I diabetes?}

Our studies led us to hypothesize that normal mouse pancreas development, based on epithelial-mesenchymal interaction, is characterized by a transient inflammatory process that takes place during the postnatal period. Underlying inflammation has recently been proposed as an event during organogenesis of the lymphopoietic-hematopoietic system, based on hematopoietic cell-mesenchymal cell interactions (41). In the pancreas, all kinds of partners exist (Figure 4): epithelial cells forming ducts and ductules, among which are the precursors of endocrine and exocrine tissues; mesenchymal cells, represented by fibroblasts, and he- matopoietic cells, mainly represented by different types of $\mathrm{M} \phi$ and a few DC. Moreover, innervation appears to be a widespread component of the developing pancreas. Some of these structures possibly represent the socalled "neuro-insular" complexes which were described many years ago and disappear with age (42). Their presence is intriguing, in light of their localization at the ductularvascular pole of the islet and at its periphery in contact with the early infiltrating APC, their labeling by Fas and Bcl-2, and the fact that various molecules are common to neural and $B$ cells and antibodies to them are found in type I diabetes (1).

If any or many of the cell type(s) involved in pancreas development do not function normally, the underlying inflammatory process may go awry. As mentioned above, hematopoietic cells such as $\mathrm{M} \phi$ and eosinophils participate in ductal branching during postnatal mouse mammary gland development (27); such a mechanism may also occur in the pancreas. Moreover, M $\phi$ are able to produce many factors (cytokines, growth factors, metalloproteinases) potentially involved

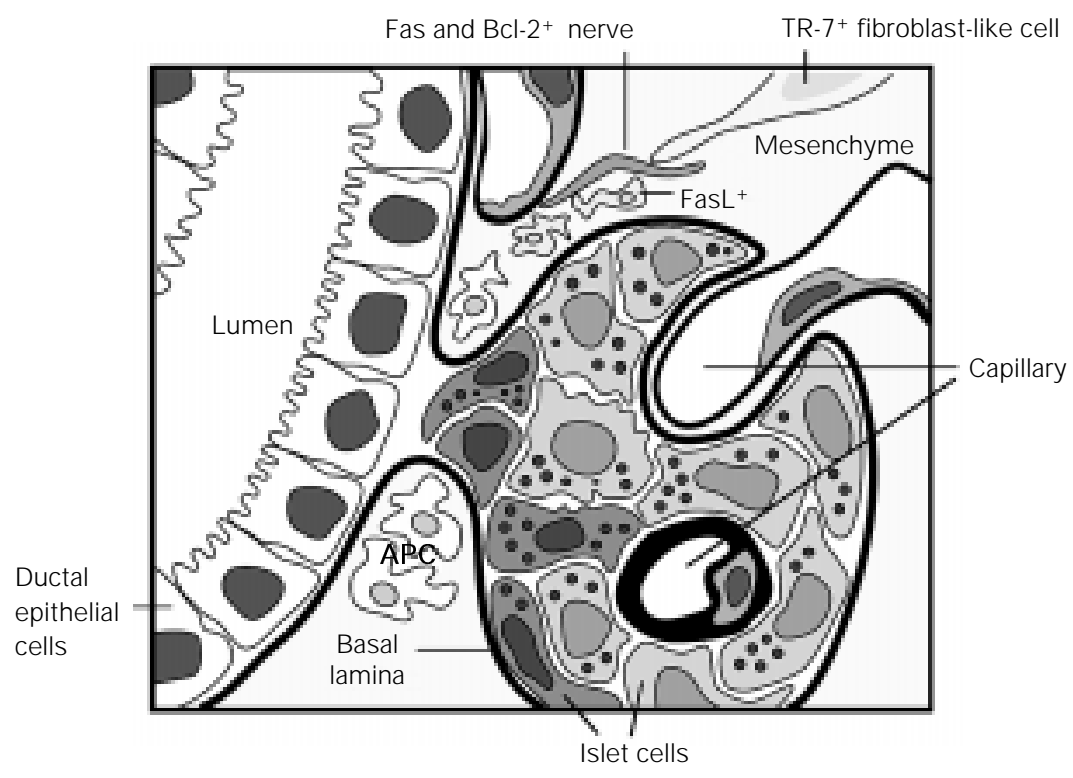

Figure 4 - Antigen-presenting cells (APC) as candidates for tissue remodeling phenomena (ECM synthesis/degradation, apoptosis) during islet neogenesis. Adapted from Pictet and Rutter (14). 
in pancreas development, and particularly islet differentiation (21). Their localization around ducts, islets and at the ductular-vascular pole of the islet makes them good candidates for roles in remodeling phenomena in vivo, comprising islet neogenesis. Several genetic and functional defects have been described at the APC level in NOD mice, including abnormal differentiation and function, such as antigen presentation, decreased cytokine secretion and enhanced arachidonic acid metabolism, and defective Fc $\gamma$ RII gene expression (43-48). Their resulting inefficacy might explain the aberrant presence of $\mathrm{FasL}^{+}, \mathrm{Bcl}-2^{+}$and $\mathrm{TR}-7^{+}$cells in NOD mice in the same localizations as APC.

Until now, while the role of the mesenchyme has been well recognized in in vitro pancreas development, the localization of fibroblasts has been overlooked in vivo. However, these cells are among the most common in tissues, participate in the production of ECM proteins and are actively engaged in the recovery from tissue damage and inflammation (49). During early postnatal pancreas development, we systematically found fibroblasts together with the ECM molecules they synthesize at the periphery of islets undergoing neogenesis and the ducts from which they derive. Recently, these cells, like "sentinel" cells, have been shown to synthesize chemokines that appear to be an important link between innate and adaptive immunity (49). Moreover, the ECM serves as a specialized reservoir for cytokines and growth factors that promote cell proliferation, differentiation, activation, migration and apoptosis $(24,50)$. The ECM microenvironment also possesses a myriad of signals that dialogue with immune cells, coordinating their behavior as they make their way into inflamed tissue (50). It is presently not known whether fibroblasts are able to communicate normally with APC and/or ductal epithelial cells during NOD pancreas development. However, it has already been suggested that the diabetic defect(s) can arise from extrapancreatic cells of mesenchymal origin (51).

It is not clear whether lymphocytes may also participate in normal pancreas development; however, their presence has been described in human fetal pancreata $(25,52)$. Pertinently, this infiltration consists of large focal infiltrates of T cells and DC/M $\phi$, localized in the connective tissue of septa and capsule of the pancreas. Later, from birth to around weaning, they might be involved in peripheral tolerance as already described for skin epithelium (53). In NOD mice, the potential anomalies at lymphocyte levels include deficient central tolerance (54), which favors autoimmunity, and resistance to apoptosis $(55,56)$, which can lead to the in situ accumulation of autoreactive and naive lymphocytes. Moreover, Fas/FasL-induced apoptosis is also critical for tolerance induction, and its dysregulation may also trigger autoimmune processes (57).

Finally, the main notion that can be derived from these findings is that type I diabetes might be a disease of pancreas development and particularly of islet neogenesis. This possibility could reasonably explain why type I diabetes 1 ) is principally a disease of childhood; 2) is affected by various gestational events, and 3) emerges when glucose homeostasis is perturbed with increased insulin demand (puberty, pregnancy, infections, stressful events) $(1,3)$. The hypothesis of altered pancreas development in type I diabetes may lead to a better understanding of 1) the multiplicity of the potential autoantigens; 2) the nonspecificity of islet cell antibodies (ICA) and islet cell surface antibodies, recognizing islet cells other than $\beta$ cells; 3) the presence of autoantibodies recognizing molecules common to $\beta$ cells and nerves, such as glutamic acid decarboxylase (GAD), and 4) the presence, in the fetal pancreas, of some type I diabetes-associated antigens (GAD65, ICA69) in epithelial and/or ductal cells $(1,58,59)$.

But how can we explain the apparent $B-$ cell specificity of the disease? First, $\beta$ cells 
play a crucial role in the organism. Second, hyperactive $\beta$ cells are more susceptible to aggression: hyperactive endocrine cells are more prone to autoimmune reactions because of higher surface expression of autoantigens and adhesion and MHC molecules, and because of an enhanced sensitivity to cytokine-induced damage (4). In the case of increased insulin demand and hyperactivity, there is a fine balance between islet neogenesis and B-cell apoptosis (60). In NOD neonates, $B$-cell hyperactivity together with islet neogenesis and B-cell apoptosis, is already present, thereby exposing potential autoantigens $(8,9)$. The different waves of NOD $\beta$ cell hyperactivity appear to be triggered by maternal abnormalities of glucose homeostasis and normal dietary changes, which take place during the weaning period. Later, during the progression of the autoimmune reaction, and because of a defective islet neogenesis attributable to immune cell abnormalities, the exhausted and finally dying $B$ cells would not be replaced, leading to the clinical onset of the disease.

\section{Acknowledgments}

The author wants to thank: V. Alves, J. Coulaud, S. Durant, A. Esling and J.M. Pleau for their daily contributions to her laboratory at CNRS UMR 8603 and I. Cissé at INSERM U25; A. Amrani, S. Charré, S. Geutskens,
A.M. Jansen, C. Pelegri, J. Rosmalen, F. Saravia-Fernandez, S. von Bockland and M. Throsby who worked or are working with enthusiasm as doctoral and postdoctoral fellows in her laboratory and/or in those of Prof. H.A. Drexhage and Dr. M. Versnel in the Department of Immunology of the Erasmus University of Rotterdam, supported by successive INSERM-NWO grants and two EC grants, "Betimmune" and "Monodiab"; Prof. H.A. Drexhage, Dr. P. Leenen, Prof. W. van Ewijk and Dr. M. Versnel from the Department of Immunology of the Erasmus University of Rotterdam, for fruitful associations and discussions, and also Dr. G.J. Bruining and Dr. R.R. de Krijger from Sophia Kinder Zievenhuis, and Joséphine Nefkens Institute, University Hospital Rotterdam; Dr. W. Savino from the Department of Immunology, Oswaldo Cruz Foundation of Rio de Janeiro, for his enthusiastic participation in the context of an INSERM-CNPq grant; Dr. M.G. HumphreysBeher from the Department of Oral Biology, University of Florida at Gainesville, for working on the same hypothesis in the NOD salivary gland and for fruitful collaborative work; Prof. C. Boitard, Dr. M. Dardenne, Dr. H.J. Garchon, Dr. R. Scharfmann and Prof. J. Timsit for their interest and helpful discussions, and Dr. H. Feillet for her excellent bibliographical assistance.

\section{References}

1. Homo-Delarche F (1997). Beta-cell behaviour during the prediabetic stage. Part II. Non-insulin-dependent and insulin-dependent diabetes mellitus. Diabetes and Metabolism, 23: 473-505.

2. Bach J F (1994). Insulin-dependent diabetes mellitus as an autoimmune disease. Endocrine Reviews, 15: 516-542.

3. Dahlquist $\mathrm{G}$ (1998). The aetiology of type 1 diabetes: an epidemiological perspective. Acta Paediatrica, 425: 5-10.

4. Homo-Delarche F \& Boitard C (1996). Autoimmune diabetes: the role of the islets of Langerhans. Immunology Today, 17:
456-460.

5. J ansen A, Homo-Delarche F, Hooijkaas $H$, Leenen PJ , Dardenne M \& Drexhage HA (1994). Immunohistochemical characterization of monocytes-macrophages and dendritic cells involved in the initiation of the insulitis and beta-cell destruction in NOD mice. Diabetes, 43: 667-675.

6. Rosmalen J GM, Homo-Delarche F, Durant $S$, Kap M, Leenen PJ M \& Drexhage HA (2000). Islet abnormalities associated with an early influx of dendritic cells and macrophages in NOD and NODscid mice. Laboratory Investigation, 80: 769-777.
7. Rosmalen J GM, Martin T, Dobbs C, Voerman J SA, Drexhage HA, Haskins K \& Leenen PJ M (2000). Subsets of macrophages and dendritic cells in non-obese diabetic mouse pancreatic inflammatory infiltrates: correlation with the development of diabetes. Laboratory Investigation, 80: 1-8.

8. Trudeau J D, Dutz J $P$, Arany E, Hill DJ , Fieldus WE \& Finegood DT (2000). Neonatal ß-cell apoptosis. A trigger for autoimmune diabetes? Diabetes, 49: 1-7.

9. Pelegri $C$, Rosmalen JGM, Durant $S$, Throsby M, Alves V, Coulaud J, Esling A, 
Pléau J M, Drexhage HA \& HomoDelarche F (2001). Islet endocrine-cell behavior from birth onwards in mice with the nonobese diabetic genetic background. Molecular Medicine (in press).

10. Charre S, Rosmalen J, Throsby M, Drexhage $\mathrm{H}$, Leenen $\mathrm{P}$, Alves $\mathrm{V}$, Dardenne $\mathrm{M}$ \& Homo-Delarche $F$ (1999). La périinsulite n'est pas un phénomène spécifique du diabète de type I, mais un phénomène normal du développement du pancréas. Diabetes and Metabolism, 25 (Suppl 1): 26 (Abstract).

11. Fernandes CA, King LC, Guz Y, Stein R, Wright CV \& Teitelman G (1997). Differentiation of new insulin-producing cells is induced by injury in adult pancreatic islets. Endocrinology, 138: 1750-1762.

12. Amrani A, Durant $S$, Throsby M, Coulaud J, Dardenne $M \&$ \& Homo-Delarche $F$ (1998). Glucose homeostasis in the nonobese diabetic mouse at the prediabetic stage. Endocrinology, 139: 1115-1124.

13. Saravia-Fernandez F, Faveeuw C, Blasquez-Bulant C, Tappaz M, Throsby M, Pelletier G, Vaudry H, Dardenne $M$ \& Homo-Delarche F (1996). Localization of gamma-aminobutyric acid and glutamic acid decarboxylase in the pancreas of the non-obese diabetic mouse. Endocrinology, 137: 3497-3506.

14. Pictet R \& Rutter WJ (1972). Development of the embryonic endocrine pancreas. In: Geiger SR (Editor), Handbook of Physiology. Section 7: Endocrinology. Vol. 1. Waverley Press, Baltimore, MD, 25-66.

15. Ferrand N, Astesano A, Phan HH, Lelong C \& Rosselin G (1995). Dynamics of pancreatic cell growth and differentiation during diabetes reversion in STZ-treated newborn rats. American J ournal of Physiology, 269: C1250-C1264.

16. Gittes GK, Galante PE, Hanahan D, Rutter WJ \& Debas HT (1996). Lineage-specific morphogenesis in the developing pancreas: role of mesenchymal factors. Development, 122: 439-447.

17. Miralles $F$, Battelino $T$, Czernichow $P \&$ Scharfmann R (1998). TGF-ß plays a key role in morphogenesis of the pancreatic islets of Langerhans by controlling the activity of the matrix metalloproteinase MMP-2. J ournal of Cell Biology, 143: 827836.

18. St Onge L, Wehr R \& Gruss P (1999). Pancreas development and diabetes. Current Opinion in Genetics and Development, 9: 295-300.

19. Finegood DT, Scaglia $L \&$ Bonner-Weir S (1995). Dynamics of beta-cell mass in the growing rat pancreas. Estimation with a simple mathematical model. Diabetes, 44 : 249-256.

20. Gu D \& Sarvetnick N (1993). Epithelial cell proliferation and islet neogenesis in IFNgamma transgenic mice. Development, 118: 33-46.

21. Bouwens L \& Kloppel G (1996). Islet cell neogenesis in the pancreas. Virchows Archiv, 427: 553-560.

22. Esni $\mathrm{F}$, Taljedal IB, Perl AK, Cremer $\mathrm{H}$, Christofori G \& Semb H (1999). Neural cell adhesion molecule (N-CAM) is required for cell type segregation and normal ultrastructure in pancreatic islets. J ournal of Cell Biology, 144: 325-337.

23. Hisaoka $M$, Haratake $J \&$ Hashimoto $H$ (1993). Pancreatic morphogenesis and extracellular matrix organization during rat development. Differentiation, 53: 163172.

24. Werb Z (1997). ECM and cell surface proteolysis: regulating cellular ecology. Cell, 91: 439-442.

25. Liu MH \& Potter EL (1962). Development of the human pancreas. Archives of Pathology, 74: 439-452.

26. Wilders $M M$, Sminia $T \&$ J anse $E M$ (1983). Ontogeny of non-lymphoid and lymphoid cells in the rat gut with special reference to large mononuclear la-positive dendritic cells. Immunology, 50: 303314.

27. Gouon-Evans V, Rothenberg ME \& Pollard J W (2000). Postnatal mammary gland development requires macrophages and eosinophils. Development, 127: 22692282.

28. J iang FX, Cram DS, Deaizpurua HJ \& Harrison LC (1999). Laminin-1 promotes differentiation of fetal mouse pancreatic B cells. Diabetes, 48: 722-730.

29. Hulinsky I, Cooney S, Harrington J \& Silink M (1995). In vitro growth of neonatal rat islet cells is stimulated by adhesion to matrix. Hormone and Metabolic Research, 27: 209-215.

30. Montesano R, Mouron $P$, Amherdt $U$ \& Orci $L$ (1983). Collagen matrix promotes reorganization of pancreatic endocrine cell monolayers into islet-like organoids. J ournal of Cell Biology, 97: 935-939.

31. Crisera CA, Kadison AS, Breslow GD, Maldonado TS, Longaker MT \& Gittes GK (2000). Expression and role of laminin-1 in mouse pancreatic organogenesis. Diabetes, 49: 936-944.

32. Lee MS, Gu D, Feng L, Curriden S, Arnush M, Krahl T, Gurushanthaiah D, Wilson C, Loskutoff DL, Fox $\mathrm{H} \&$ \& Sarvetnick N (1995). Accumulation of extracellular matrix and development dysregulation in the pancreas by transgenic production of transforming growth factor-ß1. American J ournal of Pathology, 147: 42-52.

33. De Sousa M, Tilney NL \& KupiecWeglinski J W (1991). Recognition of self within self: specific lymphocyte positioning and the extracellular matrix. Immunology Today, 12: 262-266.

34. Davis GE, Bayless KJ, Davis MJ \& Meininger GA (2000). Regulation of tissue injury responses by the exposure of matricryptic sites within extracellular matrix molecules. American J ournal of $\mathrm{Pa}$ thology, 156: 1489-1498.

35. Suniara RK, Jenkinson EJ \& Owen JJ (2000). An essential role for thymic mesenchyme in early $T$ cell development. J ournal of Experimental Medicine, 191: 1051-1056.

36. Saotome T, Inoue H, Fujimiya M, Fujiyama Y \& Bamba T (1997). Morphological and immunocytochemical identification of periacinar fibroblast-like cells derived from human pancreatic acini. Pancreas, 14: 373-382.

37. Cutler LS (1990). The role of extracellular matrix in the morphogenesis and differentiation of salivary glands. Advances in Dental Research, 4: 27-33.

38. Chal S, van Blockland SCA, Versnel MA, Homo-Delarche F, Brayer J, Peck AB \& Humphreys-Beher MG (2001). Abnormal organogenesis in salivary gland development may initiate adult onset of autoimmune exocrinopathy. Experimental and Clinical Immunogenetics (in press).

39. Tadmor B, Putterman C \& Naparstek Y (1992). Embryonal germ-layer antigens: target for autoimmunity. Lancet, 339: 975978.

40. Sakata KM, Sakada A, Kong L, Dang H \& Talal N (1998). Role of Fas/FasL interaction in physiology and pathology: the good and the bad. Clinical Immunology and Immunopathology, 87: 1-7.

41. Nishikawa SI, Hashi H, Honda K, Fraser S $\&$ Yoshida H (2000). Inflammation, a prototype for organogenesis of the lymphopoietic/hematopoietic system. Current Opinion in Immunology, 12: 342-345.

42. Fujita T (1959). Histological studies on the neuro-insular complex in the pancreas of some mammals. Zeitschrift für Zellforschung und Mikroskopische Anatomie, 50: 94-109.

43. Drexhage HA, Delemarre FGA, Radosevic $K$ \& Leenen PJ M (1999). Dendritic cells in autoimmunity. In: Lotze MT \& Thomson AW (Editors), Dendritic Cells: Biology and Clinical Applications. Academic Press, San Diego, 361-401. 
44. Serreze DV, Gaskins HR \& Leiter EH (1993). Defects in the differentiation and function of antigen presenting cells in NOD/Lt mice. J ournal of Immunology, 150: 2534-2543.

45. Piganelli J D, Martin T \& Haskins K (1998). Splenic macrophages from the NOD mouse are defective in the ability to present antigen. Diabetes, 47: 1212-1218.

46. Radosevic K, Casteels KM, Mathieu C, van Ewijk W, Drexhage HA \& Leenen PJ (1999). Splenic dendritic cells from the non-obese diabetic mouse induce a prolonged proliferation of syngeneic $T$ cells. A role for an impaired apoptosis of NOD T cells? J ournal of Autoimmunity, 13: 373382.

47. Léty MA, Coulaud J, Bens M, Dardenne M \& Homo-Delarche F (1992). Enhanced metabolism of arachidonic acid by macrophages from non-obese diabetic (NOD) mice. Clinical Immunology and Immunopathology, 64: 188-196.

48. Luan J J, Monteiro RC, Sautes C, Fluteau G, Eloy L, Fridman WH, Bach JF \& Garchon HJ (1996). Defective Fc gamma RII gene expression in macrophages of NOD mice: genetic linkage with up-regulation of IgG1 and IgG2b in serum. J ournal of Immunology, 157: 4707-4716.

49. Lo D, Feng L, Li L, Carson MJ , Crowley M, Pauza M, Nguyen A \& Reilly CR (1999). Integrating innate and adaptive immunity in the whole animal. Immunological Reviews, 169: 225-239.

50. Vaday GG \& Lider O (2000). Extracellular matrix moieties, cytokines, and enzymes: dynamic effects on immune cell behavior and inflammation. J ournal of Leukocyte Biology, 67: 149-159.

51. Goldstein S, Moerman EJ, Soeldner J S, Gleason RE \& Barnett DM (1979). Diabetes mellitus and genetic prediabetes. Decreased replicative capacity of cultured skin fibroblasts. J ournal of Clinical Investigation, 63: 358-370.

52. J ansen A, Voorbij HA, J eucken PHM, Bruining GJ , Hooijkaas $H$ \& Drexhage HA (1993). An immunohistochemical study on organized lymphoid cell infiltrates in fetal and neonatal pancreases. A comparison with similar infiltrates found in the pancreas of a diabetic infant. Autoimmunity, 15: 31-38.

53. Alferink J, Aigner S, Reibke R, Hammerling GJ \& Arnold B (1999). Peripheral Tcell tolerance: the contribution of permissive T-cell migration into parenchymal tissues of the neonate. Immunological Reviews, 169: 255-261.

54. Throsby $M$, Pleau J M, Dardenne $M$ \& Homo-Delarche F (1999). Thymic expression of the pancreatic endocrine hormones. Neuroimmunomodulation, 6: 108114.

55. Colucci F, Bergman ML, Penha-Goncalves
C, Cilio CM \& Holmberg D (1997). Apoptosis resistance of non-obese diabetic peripheral lymphocytes linked to the Idd5 diabetes susceptibility region. Proceedings of the National Academy of Sciences, USA, 94: 8670-8674.

56. Lamhamedi-Cherradi SE, Luan J J , Eloy L, Fluteau G, Bach J F \& Garchon HJ (1998). Resistance of T-cells to apoptosis in autoimmune diabetic (NOD) mice is increased early in life and is associated with dysregulated expression of Bcl-x. Diabetologia, 41: 178-184.

57. Griffith TS, Yu X, Hemdon J M, Green DR \& Ferguson TA (1996). CD95-induced apoptosis of lymphocytes in an immune privileged site induces immunological tolerance. Immunity, 5: 7-16.

58. Mally MI, Cirulli V, Otonkoski T, Soto $G \&$ Hayek A (1996). Ontogeny and tissue distribution of human GAD expression. Diabetes, 45: 496-501.

59. Mally MI, Cirulli V, Hayek A \& Otonkoski T (1996). ICA69 is expressed equally in the human endocrine and exocrine pancreas. Diabetologia, 39: 474-480.

60. Bernard C, Berthault MF, Saulnier C \& Ktorza A (1999). Neogenesis vs apoptosis as main components of pancreatic ß-cell mass changes in glucose-infused normal and mildly diabetic adult rats. FASEB J ournal, 13: 1195-1205. 